\title{
Social Mobile Gaming and User Practices
}

\section{Kemal Elciyar, Anadolu University Communication Sciences Faculty Turkey}

\begin{abstract}
Form of gaming and game area advanced with the developments occurred in ICT's. Hence game playing moved to the digital space. Computers, tablets and mobile devices became gaming tools. Mobile devices with increased power, faster communications and higher resolution displays are increasingly common to our everyday life. Today's mainstream entertainment revolves around interactivity. People want entertainment they can control and become fully involved in, a system that interacts intelligently with them and their surrounding. Powerful smartphones use various techniques such as the touch screen which users can play by intuition, or with a variety of sensors to create different ways to play. One of the top reasons why people play is participating in a social activity they can enjoy with their friends. Mobile phones are an always-carried device, they provide an excellent platform for applications. These social mobile games also allow user to interact with friends via social networks. Social mobile gaming applications generate unique and dynamic environments by creating a multidimensional and complex form of interaction among users to communicate across gaming platforms. Using the Unified Theory of Adoption and Use of Technology, a multifactorial model for technology adoption, and determinants like motivation, advertising, and game quality, this research examines the roles of these factors and how they encourage use of social mobile gaming applications.
\end{abstract}




\section{Introduction}

Mobile technology has passed an important evolutionary technological cycle. With its advance, the mobile application has cultivated itself as a superior figure in business and culture. Since its delivery in the 1970's, mobile phone technology has impressed people with its developments in human communication. (Hjorth, Burgess, \& Richardson, 2012). Media technology industries have become apparent contributors to the increasing consumer attention in smartphone technology by creating downloadable interactive software. Gartner, an information technology research and advisory company, predicts that more than 268 billion mobile apps will be downloaded by 2017 (Gartner, 2014). According to Smart Insights, 89\% of the time that users are on their media is spent on mobile applications (Bosomworth, 2014). Powerful smartphones use different techniques like touch screen, or with a variety of sensors to create different ways to play. The smartphone game has risen its popularity in recently years and many games designed for this device. Mobile devices with increased power, faster communications and higher resolution displays are increasingly common to our life. People wish entertainment they can control and become fully involved in, a system that interacts intelligently with them and their surrounding (Rodriguez, 2014). One of the top reasons why people play is participating in a social activity they can enjoy with their friends (Montola, Stenros \&Waern, 2009).

\section{Theoretical Framework}

\section{Utaut (Unified theory of acceptance and use of technology)}

When cultivating a method for analyzing adoption and use of technology, Venketesh, Morris, Davis, and Davis (2003), figured out some of the most successful theories in adoption and use. Venkatesh et al. (2003), aimed to formulate a theory that merged the most important elements of outstanding acceptance models, to create a more efficient method of explaining technology acceptance. Researchers studied behavioral and acceptance theories to combine what would become the UTAUT; these theories included: Theory of Reasoned Action (Fishbein \& Ajzen, 1975), the Technology Acceptance Model (Davis, 1985; Davis, 1989; Davis, Bagozzi, \& Warshaw 1989), the Motivational Model, (Davis et al. 1992), Theory of Planned Behavior (Ajzen,1991), combined TAM \& TPB (Taylor \& Todd, 1995), the Model of PC Utilization (MPCU) (Thompson et al. 1991), Social Cognitive Theory (Bandura, 1986) and Diffusion of Innovations (Rogers, 1995). When Venkatesh et al. (2003) first investigated 
the design for a technology acceptance hybrid, researchers found seven significant determinants directly linked to adoption or usage. Four of these constructs were linked with acceptance and usage: performance expectancy, effort expectancy, social influence and facilitating conditions. The UTAUT has served as a model and has been applied to the study of a variety of technologies (Venkatesh, Thong, \& Xu, 2012). As mentioned, SNS connection and advertising factors explain the adoption and use of mobile games.

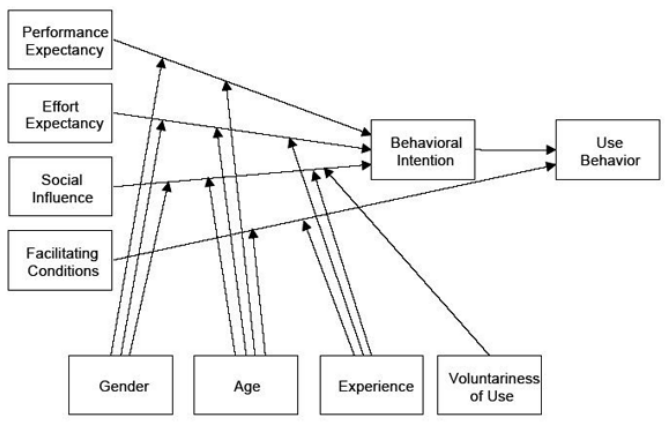

Since the development of games like Nokia's Snake in 1997 (Paul, Jensen, Wong, \& Khong, 2008; Goggin, 2010), to the currently popular 10 million plus downloaded Candy Crush Saga ${ }^{\circledR}$ (Woollaston, 2013), mobile gaming has become one of the fastest growing segments of the video-gaming industry (Paul et al., 2008). With the mobile gaming explosion, social networking sites (SNS) have also been a segment that has become a social phenomenon. As of March 2014, Facebook reported having a total of 1.28 billion active users; 1.01 million of those users active at least monthly on Facebook Mobile alone (Facebook, 2014). Because of popularity in mobile app use and easier access to social networking sites, mobile gaming companies have developed a method to integrate both concepts and create new hybrid social mobile gaming applications (SMGAs) to advertise.The SMGA industry has utilized increase in SNS interaction and gaming to persuade users into continued game use and user-driven advertising. As users are more active in games, rewards are offered based on player engagement, game referrals, game ratings, "likes", hashtags and score posting. Companies have also utilized gaming platforms for in-ad referrals and cross-promotional marketing. Users playing certain SMGAs can be informed of similar mobile games through ingame ads, SNS and banner adverting, and other games in the game play area (Fallarme, n.d.). Because of this growth and popularity in the areas of social networking, mobile gaming, and gaming advertising, these phenomena have undergone research attempts to establish what influential factors are responsible for user adoption practices and use outcome. User behavior (Park, 
Baek, Ohm, \& Chang, 2014), adoption (Christensen \& Prax, 2012) moderating factors (Zhou, 2012; Liu \& Li, 2011), user purchasing practices (Kim, Lee, \& Son, 2011), online virality and cooperation (Varga, Blazovics, Charaf, \& Fitzek, 2012), connectedness (Paul et al.,2008), and continuance (Kim, Oh, Yang, \& Kim, 2010), have all been researched as potential factors in the adoption of mobile and social mobile gaming. Despite the popularity and research attempts, there still lacks an understanding in what factors influence specifically SMGA use. SMGA users are connected to social media in these gaming platforms, exposing them to a massive virtual setting where many sources can sway use practices. Traditional elements like performance, effort, social influence, and facilitating conditions have previously been explored in the context of mobile gaming, but explanation in emerging factors like the role of user motivations, utilization of social networking sites, gaming quality, and advertising factors have not been examined in adoption of SMGAs theoretically and systematically. This study purports to fill such research voids. By applying elements drawn from the Unified Theory of Acceptance and Use of Technology (UTAUT), SNS use, ad exposure, and other contingent elements, this study examines the factors that influence use of SMGAs among users. The results of this study can provide researchers and professionals with better insight into how social media, motivation, game quality, and advertising factors, as theoretical concepts, play in SMGA use when combined with the UTAUT.

\section{Social Gaming}

Games like Snake®, created in 1997 (Paul et al., 2008; Goggin, 2010), set the precedence for mobile gaming as the standard in smartphone specifications. The casual gaming revolution has risen, ensuring a mass acceptance (Wilson, Chester, Hjorth, \& Richardson, 2011). Early mobile gaming, like Nokia's Snake ${ }^{\circledR}$, allowed users to adapt to the small interfaces that mobile phones provided (Wilson et al.). As time has progressed, screens have become larger, creating systems that are more user-friendly with touch screen technology, and have advanced graphical interfaces; this has kept the popularity of mobile gaming growing. Smartphone technologies' enhanced power, speed, and graphics, are attracting more consumer attention and reaching the demographical masses through system advancements and market diffusion (Pace, 2013). This growing demand for mobile gaming is said to be fueled by the following main factors: improved quality in video and audio, addition of more users, improved ability of wireless networks to handle broadband transmission, and the allowance of users of mobile devices to download superior and more gripping mobile gaming (Soh \& Tan, 2008). This 
advancement, combined with social network ties among users, and user exposure to game promotions (Trepte, Reinecke, \& Juechems, 2012), has allowed mobile gaming to cultivate a fusion of social networking and gaming mobile entertainment, making it more popular and increasing use.

Networking has become an activity that has taken over media technologies. Social networks empower people to build ties, keep in touch with one another, share information about one another, and create dynamic relationships online (Niyato, et al., 2011). Mobile devices have established a social medium that has produced a better method of interaction and communication among friends (Wei \& Lu, 2014). Social ties have long been a topic of attention in the area of online gaming and social network research (Huvila, Holmberg, Ek, \& Widén-Wulff, 2010) by finding correlations in online gaming to social environments created in SNS's (Trepte et al., 2012). Because of the increase in popularity, social networks like Facebook, Twitter, have penetrated the gaming platforms; creating a large group of social gaming options (Järvinen, 2009). SMGAs create a pool where technology and socialization comingle. To better understand social mobile gaming, , for the purpose of this research, we can define social mobile gaming as 'a mobile gaming application in which players collaborate and compete with one another while interacting in game play'. Emergence of social network games and studied them from various focused perspectives, such as sociability (Losh, 2008), social dynamics (Wei, Yang, \& Adamic, 2010), game design (Järvinen, 2009; Paavilainen, 2010), playability (Paavilainen, Alha, \& Korhonen, 2012, in press), platform (Kirman et al., 2010), playfulness (Kirman, 2010), marketing (Hamari \& Järvinen, 2011), behavioral economics (Hamari, 2011), player classification (Kirman \& Lawson, 2009), uses and gratifications (Hou, 2011), and motivations (Doughty, Hopkins, \& Lawson, 2011).

\section{Advertising}

The SMGAs' hybrid composition has been something that has not only attracted users but advertisers as well. In-game advertising (IGA) has been used to promote products and brands within a mobile games (Terlutter \& Capella, 2013). Terlutter and Capella analyzed in-game advertising, looking at individual and social factors that led to users' responses to game and branding. In the past, a variety of companies have merged with gaming industries for product placement within gaming. Cascadian Farms, an organic farming company, also teamed up with Farmville to advertise themselves within the game in efforts to increase brand awareness in game and in social networks (Terlutter \& Capella, 2013). A more recent tactic that has been 
used on in-game promotion has been crosspromotional campaigns. Companies and game developers create networks to build and grow games (Appstrip, 2012). This allows for the cross-promotion of gaming to a specified demographic of users interested in that gaming genre; this tactic is intended to increase use of gaming applications through game suggestions (Appstrip). This type of advertising is said to increase word of mouth promotion, and social networking promotion as users are referred to other games that fit the criteria of their current favorite platforms. These types of promotions have recently become popular among gaming app developers to increase user traffic in gaming.

\section{Constructs for Social Mobile Game Use}

\section{Motivation for Gaming (MG)}

The motivational perspective is an important factor when considering how and why users adopt and use technology. Davis et al. (1992) found that motivation was important to behavioral intention to adopt. Users can experience motivation in two ways, The first is extrinsic, which emphasizes performing a behavior to achieve a certain goal (Vallerand, 1997); this means that there must be something that the user is hoping to achieve to motivate use and engagement, the act is not solely for pleasure, but rather for the anticipation of an outcome (Lafrenière et al., 2012). The other is intrinsic, where users seek the pleasure and satisfaction from performing a behavior itself (Deci, 1975). This desire develops from users playing with anticipation of developing skill level, exploration, and engagement; this creates a sense of thrill and enjoyment (Lafrenière et al., 2012). Lafrenière et al. developed the gaming motivation scale (GAMS), to measure the presence of motivation in gaming. Adopting the GAMS, this study examines if and how motivational factors influence users' use of SMGAs. Zhou (2013), used the UTAUT and Flow Theory to help explain motivation and adoption practices among users. Flow Theory originated through research by Csikzentmihaly (1975) who investigated the experience of enjoyment within individuals as motivation in certain activities.

\section{Quality of Game (QG)}

Growth in the market of smartphones has created a robust foundation for the distribution of more sophisticated gaming options (Penttinen, Rossi, \& Tuunainen, 2010). This opens doors for game quality to improve and progress. To keep the interest of the user, these mobile apps provide updates and new features to keep the information and interface fresh. With new 
technology evolving and game quality developing, this keeps users in constant awareness with the newest features mobile apps have to offer. The quality in game growth continues introducing newer and more stimulating apps that benefit users. Designers, like those for WRC: FIA World Rally Championship, have goals to create "realistic but approachable" games with a high degree of realism to make the game more complex to play (Seif El-Nasr, Drachen, \& Canossa, 2013).

\section{Social Networking Influence-Interaction and Connectedness in Gaming (SNG)}

Interaction, connectedness, and technology were also variables studied within mobile technology adoption. In 2012, Forbes reported that Facebook had 15 million users who have purchased virtual goods, for uses such as gaming. SNS's are being utilized to enhance features on social and mobile gaming (Yung-Hui, 2012). Because of the increase in user adoption of SNS's and smartphone use, social games like Angry Birds® and Words with Friends ${ }^{\circledR}$ are becoming more accessible to users, thus attracting new gamers outside of the traditional demographics (McDermott, 2012). SNS's build communities around the game and allow for viral distribution of gaming (Feijóo et al., 2012). Through SNS use, players elicit a multi-level platform for emotional connectedness and an outlet for user entertainment and interaction. Users link to these relational ties within the social communities, by posting scores and sending game invites to initiate new users to play. Yun et al., (2013) define social influence (SI) as the degree to which an individual believes that he or she is expected to use a new technology by significant others. Social media allow users to share experiences about SMGAs through reviews and feedback shared on posts. Strong ties between attitude and behavioral intention have been connected to the use social networks as tools for supporting the purchasing decision (Di Pietro \& Pantano, 2012).

\section{Game Advertising (GA)}

Advertising has increased the potential for users to adopt of SMGAs. The book, Groundswell by $\mathrm{Li}$ and Bernoff (2008), focused on the use of new media technologies for business tactics, like advertising, and the utilization of online social media for increased user consumption of products. These authors see that more readily, consumers have relied heavily on information given through new media technologies, like SNS's and cross-promotional gaming advertisements, when choosing to adopt mobile gaming. Halligan, Shah, and Scott (2009) argue that motivating customer adoption has changed from its traditional marketing strategies. They see that prospective adopters look to new media technologies for influence. In line with 
banner adverting, advertising on social networks has become medium to broaden consumer adoption through user-generated promotions. This type of advertising encourages user to share ads across social networks (Hansen \& Lee, 2013).

\section{Methodology}

\section{Data Collection}

A secure online survey was created via Google Forms. One method used to collect participants was the use of Social Networking Sites (SNSs), Facebook. Other channels used were SMGA social chats, email blast. Study participants were offered information regarding the survey with a Google link they could follow to participate in the research effort. Participants were invited to Share the link on their respective SNSs. Participants were able to complete the survey on any computer with Internet access, $24 \mathrm{~h}$ per day, Data collection was conducted from April 15 to April 25 of 2015. Before beginning the survey, participants read and indicated their consent to participate. The survey took an average of 6 min to complete. Data were pulled from the Google website and was downloaded on to a spreadsheet. Data were then examined for incomplete surveys. Once data were cleaned for analysis, a total of 101 participant responses were used in data analysis for the purpose of this research. The data were downloaded from the Google Forms website into a Microsoft excel file and imported into the statistical analysis program SPSS to test research hypotheses.

\section{Measures}

This study explored many variables probable in being significant determinants in the behavioral intention to use SMGAs. A total of seven factors were tested, entailing the following: motivation, game quality, social network influence, advertising. Demographic factors of gender, age and education were also tested.

\section{Motivation}

Davis et al. (1992) noted that Motivation can be a strong influencer in intention. Users can experience motivation in two ways; extrinsically and intrinsically. The first is extrinsically,in which a user acts on a behavior to achieve a certain goal (Vallerand, 1997); the other is 
intrinsically; this is where a user seeks satisfaction from performing a behavior (Deci, 1975). These two characteristics of motivation were considered as eight items were created for the 7point scale that ran from 1- strongly disagree, to 7- strongly agree.

\section{Game Quality}

The ever-evolving progress in smartphone enhancements keeps users interested in smartphone technologies and mobile applications. Browne and Maire (2010), found this to be true when studying the aesthetics in mobile gaming and how users reacted to game quality. Quality has become something that must be considered in user intention to adopt SMGAs. Participants responded to six items regarding the quality of social mobile gaming applications. Items on a 7-point Likert scale extended from 1- strongly disagree, to 7- strongly agree.

\section{Social Networking Influence}

Social networks have taken advantage of the fact that 56 million Americans have played mobile games; they have done so by building online gaming communities for viral gaming distribution (O'Dell, 2011; Feijóo et al., 2012). This has led SNS's to become an outlet for social influence in SMGA use. In social influence, individuals weigh decisions heavily on the importance of others' beliefs and use that to determine if she/he should choose to adopt technology (Venkatesh et al., 2003). This study asked participants to respond to six items concerning SNS influence in SMGA adoption and use.

\section{Game Advertising}

Advertising has had to evolve with the ever growing popularity in mobile apps; this means that there has been a change in how to motivate customer adoption (Halligan, Shah, \& Scott, 2009). Cross-promotion, Tell-A-Friend, and online game referrals have become the norm. This study focuses on Advertising as a potential construct in SMGA use. Five items were used to measure if SMGA advertising influenced app adoption, arranged in a 7-point scale, with 1 - strongly disagree, to 7 - strongly agree.

\section{SMGA Usage}

Hernandez et al. (2009), argue the importance of companies knowing the difference between use and intention and the need to know which motivations influence each. Rogers (1995) and Cooper and Zmud (1990), note that the phenomenon of adoption and usage can be 
categorized into a post-acceptance stage, because users have accepted technology, used it, and integrated it as part of a normal routine (as cited in Cho, Cheng, \& Hung, 2009, p. 265).

Since this study assumes that all respondents have used SMGAs to some degree, the questionnaire included four survey items about SMGA usage.

\section{Research instruments}

The researchers used the questionnaire which used by Ana Kahnı Rodriguez, B.A for the thesis presented to the Graduate Faculty of The University of Texas in determining the level of SMGA use. Questionnaire has 31 items which includes likert scale of 1 to 7 and 3 demographic questions. Statistical Package for the Social Sciences (SPSS 22.0) was used to calculate data.

\section{Results}

\section{Motivation}

Motivation would be a positive predictor of respondent use of social mobile gaming apps. Motivation was tested in the two categories of friendship motivation and entertainment motivation. In this study, motivation was hypothesized as a factor in adoption and use. Participants in Wei and Lu's (2014) study of mobile gaming found that gaming was a form of instant entertainment, which is one of the main motivational reasons for adoption. Motivations showed positive significance in the number of SMGAs users currently owned. What can be inferred is that users rely on entertainment motivation to download SMAGAs. According to the results, there is a probability that the more entertaining an SMGA is, the more likely a user will download it. When tested against the length of time SMGAs are used, entertainment motivation, represented a positive relation.

\section{Game Quality}

Quality of game being a positive predictor of the use of social mobile gaming apps. In previous research, studies showed that quality was a main concern to demanding gamers during the purchasing process of gaming (Penttinen, Rossi, \& Tuunainen, 2010). Result showed that quality was an important feature that showed significance among respondents. This analysis discovered a positive relation with the number of SMGAs respondents used. This means that respondents utilized less SMGAs based on the quality of the game. 


\section{Social Network Influence}

Zhou (2013) found that social influence was an important influencer in adoption of mobile apps; research showed that social influence reflected a process of compliance in which users followed opinions of peers when choosing to adopt. This study hypothesized that social influence from social networking sites would be positive predictor of user adoption and use of social mobile gaming apps. Based on the analysis of participants' responses, social network influence was not significant in predicting SMGA use. Both women and men don't interested in social networks.

\section{Advertising}

Soroa-Koury and Yang (2010) reported that advertising on mobile devices could affect users towards having a favorable opinion of them. This made the willingness to accept them easier. When this factor was tested in data analysis for this research, results indicated a negative relation between ad exposure and SMGA daily use. Ad exposure negatively influences the longer time users spend on SMGAs per day.

\section{Conclusion}

Overall, this research found significance in the areas of motivation, quality, social network influence and advertising. This researched discovered that entertainment motivation was a significant factor that spanned across the number of SMGAs respondents owned, the length of time they were used, and how many hours per day users were active on SMGAs. Advertising and social network influence indicated a negative relation to how many hours per day were spent on an SMGA. Future research could focus on the limitations and incorporate other factors suggested for research. This study provided insight into the areas of mobile apps, business tactics, and gaming. Findings can be utilized among future researchers and businesses to assess the effect on user decision to engage in social mobile gaming application practice. 


\section{References}

Ajzen, I. (1991).The theory of planned behavior. Organizational behavior and human decision processes, 50(2), 179-211. doi: http://dx.doi.org/10.1016/07495978(91)90020-T

Appstrip (n.d.). Here's the plan. Retrieved from http://www.appstrip.com/the-plan

Bosomworth, D. (2014, March 24). Statistics on mobile usage and adoption to inform your mobile marketing strategy. Retrieved from http://www.smartinsights.com/mobilemarketing/mobile-marketing-analytics/mobilemarketing-statistics/.

Bandura, A. (1986). Social Foundations of Thought and Action: A Social Cognitive Theory. NewJersey: Prentice-Hall.

Davis, F. D. (1985). A Technology Acceptance Model for Empirically Testing New End-user Information Systems: Theory and Results. Boston: Massachusetts Institute of Technology.

Davis, F. D. (1989). Perceived usefulness, perceived ease of ease, and user acceptance of information technology. MIS Quarterly, 13(3), 319-340. doi: 10.2307/249008

Davis, F. D., Bagozzi, R. P., \& Warshaw, P. R. (1992). Extrinsic and intrinsic motivation to use computers in the workplace. Journal of Applied Social Psychology, 22(14), 11111132.

doi: 10.1111/j.1559-1816.1992.tb00945.x

Di Pietro, L., \& Pantano, E. (2012). An empirical investigation of social network influence on 
consumer purchasing decision: The case of Facebook. Journal of Direct, Data and Digital Marketing Practice, 14(1), 18-29. doi:

http://dx.doi.org/10.1057/dddmp.2012.10

Feijoo, C., Gómez-Barroso, J.-L., Aguado, J.-M., \& Ramos, S. (2012). Mobile gaming: Industry challenges and policy implications. Telecommunications Policy, 36(3), 212221. doi: http://dx.doi.org/10.1016/j.telpol.2011.12.004

Fishbein, M., \& Ajzen, I. (1975). Belief, Attitude, Intention, and Behavior: An Introduction to Theory and Research. Boston: Addison-Wesley Pub. Co.

Gartner (2014, January 22). Mobile Apps Will Be a Vehicle for Cognizant Computing. Retrieved from http://www.gartner.com/newsroom/id/2654115?nicam=prsm13 Goggin, G. (2010). Global Mobile Media. New York: Taylor \& Francis.

Halligan, B., Shah, D., \& Scott, D. M. (2009). Inbound Marketing: Get found using Google, social media, and blogs. New Jersey: Wiley.

Hansen, S. S., \& Lee, J. K. (2013). What drives consumers to pass along marketer-generated eWOM in social network games? Social and game factors in play. Journal of Theoretical and Applied Electronic Commerce Research, 8(1), 53-68.

Hjorth, L., Burgess, J., \& Richardson, I. (2012). Studying Mobile Media: Cultural Technologies, Mobile Communication, and the iPhone. New York: Routledge.

Huvila, I., Holmberg, K., Ek, S., \& Widén-Wulff, G. (2010). Social capital in second life. Online Information Review, 34(2), 295-316. Kim, H., Lee, H. L., \& Son, J. E. (2011). An exploratory study on the determinants of smartphone app purchase. Proceedings from the 11th International DSI and the 16th APDSI Joint Meeting. Taipei, Taiwan.

Järvinen, A. (2009). Game design for social networks: interaction design for playful dispositions.Paper presented at the Proceedings of the 2009 ACM SIGGRAPH Symposium on Video Games, New Orleans, Louisiana.

Kim, C.-S., Oh, E.-H., Yang, K., \& Kim, J. (2010). The appealing characteristics of download type mobile games. Service Business, 4(3-4), 253-269. doi: 10.1007/s11628-009-00880

Lafrenière, M.-A. K., Verner-Filion, J., \& Vallerand, R. J. (2012). Development and validation of the Gaming Motivation Scale (GAMS). Personality and Individual Differences, 53(7), 827-831. doi: http://dx.doi.org/10.1016/j.paid.2012.06.013

Liu, Y., \& Li, H. (2011). Exploring the impact of use context on mobile hedonic services 
adoption: An empirical study on mobile gaming in China. Computers in Human Behavior, 27(2), 890-898. doi: http://dx.doi.org/10.1016/j.chb.2010.11.014

McDermott, J. (2012, June, 1). Business opportunities in mobile and social gaming, Inc. Retrieved from http://www.inc.com/best-industries-2012/john-mcdermott/mobileandsocial-gaming.html

Montola, M., Stenros, J., Waern, A. 2009. Theory and Design Pervasive games, experiences on the Boundary Between Life and Play, Elsevier, The United States of America

Niyato, D., Ping, W., Saad, W., \& Hjørungnes, A. (2011). Controlled Coalitional Games for Cooperative Mobile Social Networks. Vehicular Technology, IEEE Transactions on, 60(4), 1812-1824. doi: 10.1109/TVT.2011.2116816

Paavilainen, J., Stenros, J., Kinnunen, J., \& Hamari, J. (2013). Social Network Games:

Players' Perspectives. Simulation \& Gaming, 44(6), 794-820. doi:

$0.1177 / 1046878113514808$

Pace, J. (2013). The ways we play, part 2: Mobile game changers. Computer, 46(4), 97-99. doi: 10.1109/MC.2013.146

Park, E., Baek, S., Ohm, J., \& Chang, H.J. (2014). Determinants of player acceptance of mobile social network games: An application of extended technology acceptance model. Telematics and Informatics, 31 (1), 3-15.

Paul, S. A., Jensen, M., Wong, C. Y., \& Khong, C. W. (2008). Socializing in mobile gaming. Paper presented at the Proceedings of the 3rd international conference on Digital Interactive Media in Entertainment and Arts, Athens, Greece.

Penttinen, E., Rossi, M., \& Tuunainen, V. K. (2010). Mobile games: Analyzing the needs and values of the consumers. JITTA: Journal of Information Technology Theory and Application, 11(1)

Rodriguez, A. (2014) Social Mobile Gaming Applications: User Practices In The Mobile Age. Master Thesis. The University of Texas

Rogers, E. M. (1995). Diffusion of innovations (4th ed.). New York: Free Press. Seif El-Nasr, M., Drachen, A., Canossa, A. (2013). Game Analytics: Maximizing the value of player data. London: Springer.

Soh, J. O. B., \& Tan, B. C. Y. (2008). Mobile gaming. Communication. ACM, 51(3), 35-39. doi: $10.1145 / 1325555.1325563$

Taylor, S., Todd, P.A. (1995). Understanding information technology usage: A test of competing models. Information Systems Research, 6(2), 144-176. 
Terlutter, R., \& Capella, M. L. (2013). The Gamification of Advertising: Analysis and Research Directions of In-Game Advertising, Advergames, and Advertising in Social Network Games. Journal of Advertising, 42(2/3), 95-112.

Vallerand, R.J. (1997). Toward a hierarchical model of intrinsic and extrinsic motivation. In: Advances in experimental social psychology. Ed: Zanna, M.P. New York: Academic Press. 271-360

Varga, C., Blazovics, L., Charaf, H., \& Fitzek, F. P. (2012). User cooperation, virality and gaming in a social mobile network: The Gedda-Headz concept. In A. Abraham (Ed.), Computational Social Networks (pp. 207-227). London: Springer

Venkatesh, V., Morris, M. G., Gordon, B. D., \& Davis, F. D. (2003). User acceptance of information technology: Toward a unified view. MIS Quarterly, 27(3), 425-478. doi: $10.2307 / 30036540$

Venkatesh, V., Thong, J. Y. L., \& Xu, X. (2012). Consumer acceptance and use of information technology: Extending the unified theory of acceptance and use of technology. MIS Q., 36(1), 157-178.

Wei, P.-S., \& Lu, H.-P. (2014). Why do people play mobile social games? An examination of network externalities and of uses and gratifications. Internet Research, 24(3), 313331.doi: 10.1108/IntR-04-2013-0082

Wei, P.-S., \& Lu, H.-P. (2014). Why do people play mobile social games? An examination of network externalities and of uses and gratifications. Internet Research, 24(3), 313-331. doi: 10.1108/IntR-04-2013-0082

Wilson, J., Chesher, C., Hjorth, L., \& Richardson, I. (2011). Distractedly engaged: Mobile gaming and convergent mobile media. Convergence: The International Journal of Research into New Media Technologies, 17(4), 351-355. doi:10.1177/1354856511414351

Woollaston, V. (2013, May 14). Candy Crush Saga soars above Angry Birds to become world's most popular game, Dailymail. Retrieved from http://www.dailymail.co.uk/sciencetech/article-2324228/Candy-Crush-Sagaovertakes-Angry-Birds-WORLDS-popular-game.html

Yung-Hui, L. (2012, August 2). 1.6\% Of Facebook users spent over \$1 billion on virtual goods.Forbes. Retrieved from: http://www.forbes.com/sites/limyunghui/2012/08/02/16-offacebook-users-spent-over-1-billion-on-virtual-goods/

Zhou, T. (2012). Examining location-based services usage from the perspectives of unified 
theory of acceptance and use of technology and privacy risk. Journal of Electronic Commerce Research, 13(2), 135-144.

Zhou, T. (2013). An empirical examination of the determinants of mobile purchase. Personal and Ubiquitous Computing, 17(1), 187-195. doi: 10.1007/s00779-011-0485-y 